Article

\title{
Identification of Aroma Compounds of Lamiaceae Species in Turkey Using the Purge and Trap Technique
}

\author{
Ahmet Salih Sonmezdag ${ }^{1}$, Hasim Kelebek ${ }^{2}$ and Serkan Selli ${ }^{3, *}$ \\ 1 Department of Gastronomy and Culinary Arts, Faculty of Fine Arts, Gaziantep University, \\ Gaziantep 27100, Turkey; sonmezdag@gantep.edu.tr \\ 2 Department of Food Engineering, Faculty of Engineering and Natural Sciences, \\ Adana Science and Technology University, Adana 01100, Turkey; hkelebek@adanabtu.edu.tr \\ 3 Department of Food Engineering, Faculty of Agriculture, Cukurova University, Adana 01330, Turkey \\ * Correspondence: sselli@cu.edu.tr; Tel.: +90-322-338-6173; Fax: +90-322-338-6614
}

Academic Editor: Angel A. Carbonell-Barrachina

Received: 28 October 2016; Accepted: 25 January 2017; Published: 8 February 2017

\begin{abstract}
The present research was planned to characterize the aroma composition of important members of the Lamiaceae family such as Salvia officinalis, Lavandula angustifolia and Mentha asiatica. Aroma components of the S. officinalis, L. angustifolia and M. asiatica were extracted with the purge and trap technique with dichloromethane and analyzed with the gas chromatography-mass spectrometry (GC-MS) technique. A total of 23, 33 and 33 aroma compounds were detected in Salvia officinalis, Lavandula angustifolia and Mentha asiatica, respectively including, acids, alcohols, aldehydes, esters, hydrocarbons and terpenes. Terpene compounds were both qualitatively and quantitatively the major chemical group among the identified aroma compounds, followed by esters. The main terpene compounds were 1,8-cineole, sabinene and linalool in Salvia officinalis, Lavandula angustifolia and Mentha asiatica, respectively. Among esters, linalyl acetate was the only and most important ester compound which was detected in all samples.
\end{abstract}

Keywords: aroma; purge and trap; Salvia officinalis; Lavandula angustifolia; Mentha asiatica

\section{Introduction}

Throughout human history, medicinal and aromatic plants have been used for flavor enrichment in culinary and medicinal purpose in folk medicine. Today, the usage of these plants in daily diet has increased significantly all over the world. Within this trend, the family of Lamiaceae has been of great importance due to the unique aroma and nutritional value [1]. Lamiaceae is one of the widespread and the most exclusive medicinal and aromatic family of flowering plants, containing about 220 generas and around 4000 species all over the world. Generally, this family is cultivated in the dry, mild, and cold districts of Asia, Europe and North Africa [2]. Archeological excavations showed that the usage of this family member is based on prehistoric times and harvested not only wild but also in local balances [3]. This great diversity includes the following species: lavenders, sage, and mints.

One of the most important members of the Lamiacae family is Lavenders (Lavandula spp.). This genus is native and widely distributed in the Mediterranean region. Lavandula contains sesional, medicanal shrubs and small herbs, which have aromatic parts [4]. Lavandula angustifolia is an endemic, widely distributed and taxon of the Mediterranean part of Turkey. It has a great market value owing to the strong and characteristic aroma. Thus, dry herb or essential oil of the plant is very demanded in flavoring, pharmaceutical, and food industries [5]. The Salvia L. (sage) is one of the main genera of the Lamiaceae family and contains almost 900 species all over the world, of which 94 taxa, belonging 
to 89 species, are grown in Turkey. Salvia officinalis L. is also endemic to the Mediterranean districts as a seasonal medicinal and aromatic herb. The plant has been widely used traditionally in food preparation, flavoring agents in perfumery, and cosmetics. Additionally, it has been used for medicinal purposes for a long list of diseases [6]. The Mentha spp. is another famous essential oil herb of medicinal and aromatic plants and is an important commodity owing to the huge requisitions for its volatiles oil in foodstuff, medicinal and hygiene manufactures. Globally, the genus Mints consist of 62 taxa and 18 species. Furthermore, mints have been consumed in folk medicine for the treatment of many complaints owing to its anti-inflammatory, analgesic, and sedative effects $[7,8]$.

The volatile composition of Lamiaceae is affected by several different and very heterogeneous chemicals (e.g., alcohols, aldehydes, esters, ketones, acids, terpenes, etc.). Some of the short chain terpenes that constitute the main fraction of the Lamiaceae family, especially C10 mono- and C15 sesquiterpenes, overwhelmingly affect the flavor and taste of this family [9]. This group includes some pleasant smelling volatiles and terpenes-rich herbs which are very important in culinary and perfumery industry. In addition, many of its members have anti-bacterial effects and these specialties are mainly owing to the C10 mono- and C15 sesquiterpenes in the herb [10]. To the best of our knowledge, there is some research regarding the essential oil of these three members of Lamiaceae but no combined clarification of information from GC and gas chromatography-mass spectrometry (GC-MS) analysis, has been conducted on the aroma composition of Turkish origin.

Therefore, the aim of the present research was to identify and quantify the volatile composition of three members, Salvia officinalis, Lavandula angustifolia and Mentha asiatica, of the Lamiaceae family, all of which are cultivated in Turkey. In the present study, the aroma extraction method selected was the purge and trap technique with dichloromethane solvent. This technique is a very sensitive extraction method for many aroma compounds, especially with low boiling points. Additionally, by using this technique, it is possible to extract volatile compounds without artifacts formation with high reliability gas chromatography (GC) together with mass spectrometry (MS) and a flame ionization detector (FID) for quantification and identification of volatile compounds.

\section{Materials and Methods}

\subsection{Samples and Chemicals}

Commercial samples (1 kg) of dried young leaves of Salvia officinalis, Lavandula angustifolia and Mentha asiatica (origin: Turkey) were obtained from a local herbalist supplier, in Gaziantep, Turkey in July 2016. The herbs were identified by the Faculty of Agriculture, University of Cukurova. The moisture content of the herbs was 3.7\%-4.5\% (dry basis). Water used in this study was purified by a Millipore-Q system (Millipore Corp., Saint-Quentin, France). The standard volatile compounds were purchased from Sigma-Aldrich (Steinheim, Germany). Dichloromethane, sodium sulfate and 4-nonanol were obtained from Merck (Darmstad, Germany). Dichloromethane was freshly distilled prior to use.

\subsection{Extraction of Volatile Compounds}

Volatiles of herbs were extracted by the purge and trap system which comprises a flow-meter which controls a nitrogen source and is connected to a splitter system to divide the flow into several channels in order to purge three samples at the same time. Lichrolut EN tubes obtained from Merck were used as an adsorbent which is one of most appropriate sorbents for volatile compounds extraction with respect to the previous research [11]. The herb samples were previously mortared and placed into a $20 \mathrm{~mL}$ vial; then, the sample was pre-incubated at optimized purging temperature $\left(60^{\circ} \mathrm{C}\right)$ for $10 \mathrm{~min}$. The process was applied for $90 \mathrm{~min}$ with a nitrogen flow of $500 \mathrm{~mL} / \mathrm{min}$. After purging, the volatiles held in the cartridge were eluted with dichloromethane. The elute was dried by anhydrous sodium sulphate; the pooled organic extract was concentrated to $5 \mathrm{~mL}$ in a Kuderna Danish concentrator fitted with a Snyder column at $40{ }^{\circ} \mathrm{C}$ (Supelco, St. Quentin, France) and then to $0.5 \mathrm{~mL}$ under a gentle flow 
of nitrogen. Extracts were then stored at $-20^{\circ} \mathrm{C}$ in a glass vial equipped with a Teflon-lined cap until analysis. Extractions were carried out in triplicate [12].

\subsection{GC-FID, GC-MS Analysis of Volatile Compounds}

Agilent 6890 chromatograph interfaced with a flame ionization detector (FID) and Agilent 5973-Network-mass selective detector (MSD) (Wilmington, Delaware, DE, USA) constituted the gas chromatography (GC) system. DB-Wax column ( $30 \mathrm{~m}$ length $\times 0.25 \mathrm{~mm}$ i.d. $\times 0.5 \mu \mathrm{m}$ thickness, J\&W Scientific, Folsom, CA, USA) were used to separate volatile compounds. An amount of $3 \mu \mathrm{L}$ of extract was injected in pulsed splitless ( $40 \mathrm{psi} ; 0.5 \mathrm{~min}$ ) mode. Injector and FID detectors were set at $270{ }^{\circ} \mathrm{C}$ and $280^{\circ} \mathrm{C}$, respectively. The flow rate of carrier gas (helium) was $1.5 \mathrm{~mL} \cdot \mathrm{min}^{-1}$. The conditions of the oven program of the DB-Wax column was $50{ }^{\circ} \mathrm{C}$ to $250{ }^{\circ} \mathrm{C}$ at $4{ }^{\circ} \mathrm{C} / \mathrm{min}, 10 \mathrm{~min}$ hold. As for the mass-selective detector, the identical oven program was used. The MS (electronic impact ionization) conditions were as follows: ionization energy of $70 \mathrm{eV}$, mass range $\mathrm{m} / \mathrm{z}$ of $30-300$ a.m.u., scan rate of $2.0 \mathrm{scan} \cdot \mathrm{s}^{-1}$, interface temperature of $250{ }^{\circ} \mathrm{C}$, and source temperature of $180{ }^{\circ} \mathrm{C}$. The volatile compounds were analyzed in full scan mode and assigned by comparison of their retention index and their mass spectra on the DB-Wax column with those of a commercial spectra database (Wiley 6, NBS $75 \mathrm{k}$ ) and the instrument's internal library made through the aforementioned laboratory researches. After identification, the internal standard method with 4-nonanol was used to determine the mean value of volatile compounds and mean values ( $\mu \mathrm{g} 100 \mathrm{~g}^{-1}$ dry weight; $\mathrm{dw}$ ) of the triplicate of GC analyses were calculated for each sample. By using $n$-alkane $\left(C_{8}-C_{32}\right)$ series, retention indices of the compounds were calculated [12,13].

\section{Results and Discussion}

GC-MS investigation of the volatiles extracted from three members of the Lamiaceae family by employing the purge and trap extraction method allowed the identification of a total of 66 compounds (Figure 1). As shown in Table 1, a total of 23 volatiles were detected in Salvia officinalis extract, while in Lavandula angustifolia and Mentha asiatica 33 volatiles were extracted. These compounds were classified based on their chemical characteristics: acids, alcohols, aldehydes, esters, hydrocarbons and terpenes. Mean values ( $\mu \mathrm{g} 100 \mathrm{~g}^{-1} \mathrm{dw}$ ) of the triplicate of GC analyses were calculated. The highest concentration was found in L. angustifolia $\left(70,695.1 \mu \mathrm{g} 100 \mathrm{~g}^{-1} \mathrm{dw}\right)$ followed by M. asiatica $\left(470,653 \mu \mathrm{g} 100 \mathrm{~g}^{-1} \mathrm{dw}\right)$ and S. officinalis ( $45691.0 \mu \mathrm{g} 100 \mathrm{~g}^{-1} \mathrm{dw}$ ) showing the difference of genera on the concentration of compounds detected. When the genera were compared, the major variance was detected at the mean values of volatiles in the L. angustifolia, which was greater than in M. asiatica and S. officinalis.

Among the aroma compounds, terpenes were quantitatively and qualitatively the most abundant volatiles detected in the three members of the Lamiaceae family. Many plants and parts of them are well known with their pleasant odors, spicy tastes or to show pharmacological activities due to the terpene compounds. These specialties are formed predominantly by terpenes. However, producing purposes and biological functions of these compound have not been completely inspected. Many herbs generate terpenes so as to charm insects for pollination or to protect herbs from being eaten by animals [10]. A total of 43 terpenes were detected and quantified in the herb extracts: 17 detected in S. officinalis, 18 in L. angustifolia and 25 in M. asiatica.

Our results are in accordance with MÉNDEZ-TOVAR, et al. [14] who observed the main aroma compound of wild populations of Labiatae species as oxygenated monoterpenes. Within these, terpene $\beta$-myrcene and caryophyllene compounds were the only terpene compounds identified in all studied herbs. The mean value of the terpene compounds in L. angustifolia $\left(47,635 \mu \mathrm{g} 100 \mathrm{~g}^{-1} \mathrm{dw}\right)$ was higher than in S. officinalis $\left(44,055 \mu \mathrm{g} 100 \mathrm{~g}^{-1} \mathrm{dw}\right)$ and M. asiatica $\left(37,501 \mu \mathrm{g} 100 \mathrm{~g}^{-1} \mathrm{dw}\right)$. The main terpene compounds in S. officinalis were 1,8-cineole, $\alpha$-pinene and $\beta$-pinene. The total concentration of these compounds was $21,341 \mu \mathrm{g} 100 \mathrm{~g}^{-1} \mathrm{dw}, 4233 \mu \mathrm{g} 100 \mathrm{~g}^{-1} \mathrm{dw}$ and $3044 \mu \mathrm{g} 100 \mathrm{~g}^{-1} \mathrm{dw}$, respectively, and accounted for $64 \%$ of the total terpene compounds identified in S. officinalis. 
Table 1. Aroma compounds of Salvia officinalis Lavandula angustifolia and Mentha asiatica.

\begin{tabular}{|c|c|c|c|c|c|c|c|c|}
\hline \multirow{2}{*}{ No } & \multirow{2}{*}{ LRI * } & \multirow{2}{*}{ Chemical Class } & \multirow{2}{*}{ Sum Formula } & \multirow{2}{*}{ Compounds } & \multicolumn{3}{|c|}{ Concentration $\left(\mu \mathrm{g} 100 \mathrm{~g}^{-1} \mathrm{dw}\right)^{\#}$} & \multirow{2}{*}{ Identification $\S$} \\
\hline & & & & & Salvia officinalis & Lavandula angustifolia & Mentha asiatica & \\
\hline 1 & 1008 & Alcohol & $\mathrm{C}_{5} \mathrm{H}_{10} \mathrm{O}$ & 2-Methyl-3-buten-2-ol & nd & $309 \pm 9.27$ & nd & LRI, MS, tent \\
\hline 2 & 1027 & Terpene & $\mathrm{C}_{10} \mathrm{H}_{16}$ & $\alpha$-Pinene & $4233 \pm 97.3$ & $240 \pm 5.52$ & nd & LRI, MS, std \\
\hline 3 & 1038 & Terpene & $\mathrm{C}_{10} \mathrm{H}_{16}$ & $\alpha$-Thujene & nd & nd & $2290 \pm 38.9$ & LRI, MS, tent \\
\hline 4 & 1075 & Ester & $\mathrm{C}_{6} \mathrm{H}_{12} \mathrm{O}_{2}$ & $n$-Butyl acetate & $178 \pm 6.05$ & $169 \pm 5.74$ & nd & LRI, MS, tent \\
\hline 5 & 1082 & Aldehyde & $\mathrm{C}_{6} \mathrm{H}_{12} \mathrm{O}$ & Hexanal & nd & nd & $304 \pm 12.7$ & LRI, MS, std \\
\hline 6 & 1087 & Terpene & $\mathrm{C}_{10} \mathrm{H}_{16}$ & Camphene & $2098 \pm 52.4$ & $681 \pm 17.0$ & nd & LRI, MS, std \\
\hline 7 & 1108 & Alcohol & $\mathrm{C}_{4} \mathrm{H}_{10} \mathrm{O}_{2}$ & 1-Methoxy-2-propanol & nd & $38.9 \pm 1.32$ & nd & LRI, MS, tent \\
\hline 8 & 1124 & Terpene & $\mathrm{C}_{10} \mathrm{H}_{16}$ & $\beta$-Pinene & $3044 \pm 124$ & $208 \pm 8.52$ & nd & LRI, MS, std \\
\hline 9 & 1130 & Hydrocarbon & $\mathrm{C}_{8} \mathrm{H}_{10}$ & $m$-Xylene & nd & $137 \pm 2.87$ & nd & LRI, MS, std \\
\hline 10 & 1134 & Terpene & $\mathrm{C}_{10} \mathrm{H}_{16}$ & Sabinene & nd & nd & $7091 \pm 219$ & LRI, MS, std \\
\hline 11 & 1153 & Alcohol & $\mathrm{C}_{5} \mathrm{H}_{10} \mathrm{O}$ & 3-Penten-2-ol & $75.3 \pm 2.25$ & $91.5 \pm 2.74$ & nd & LRI, MS, tent \\
\hline 12 & 1167 & Terpene & $\mathrm{C}_{10} \mathrm{H}_{16}$ & $\beta$-Myrcene & $2573 \pm 59.1$ & $519 \pm 11.9$ & $1688 \pm 38.8$ & LRI, MS, std \\
\hline 13 & 1072 & Terpene & $\mathrm{C}_{10} \mathrm{H}_{16}$ & Camphene & $2881 \pm 48.9$ & nd & $275 \pm 4.67$ & LRI, MS, std \\
\hline 14 & 1178 & Terpene & $\mathrm{C}_{10} \mathrm{H}_{16}$ & $\alpha$-Terpinene & nd & nd & $3788 \pm 128$ & LRI, MS, std \\
\hline 15 & 1190 & Terpene & $\mathrm{C}_{10} \mathrm{H}_{16}$ & dL Limonene & nd & nd & $1537 \pm 64.5$ & LRI, MS, std \\
\hline 16 & 1199 & Terpene & $\mathrm{C}_{10} \mathrm{H}_{18} \mathrm{O}$ & 1,8-Cineole & $21341 \pm 533$ & $6160 \pm 154$ & nd & LRI, MS, tent \\
\hline 17 & 1225 & Terpene & $\mathrm{C}_{10} \mathrm{H}_{16} \mathrm{O}$ & $\beta$-Thujene & nd & nd & $1485 \pm 50.4$ & LRI, MS, tent \\
\hline 18 & 1260 & Terpene & $\mathrm{C}_{10} \mathrm{H}_{16}$ & $\beta$-Ocimene & $217 \pm 8.89$ & $453 \pm 18.5$ & nd & LRI, MS, tent \\
\hline 19 & 1265 & Terpene & $\mathrm{C}_{10} \mathrm{H}_{16}$ & $\gamma$-Terpinene & $919 \pm 19.2$ & nd & $6588 \pm 138$ & LRI, MS, std \\
\hline 20 & 1272 & Terpene & $\mathrm{C}_{10} \mathrm{H}_{14}$ & $o$-Cymene & nd & nd & $701 \pm 21.7$ & LRI, MS, std \\
\hline 21 & 1280 & Terpene & $\mathrm{C}_{10} \mathrm{H}_{14}$ & $p$-Cymene & nd & $683 \pm 20.4$ & nd & LRI, MS, std \\
\hline 22 & 1285 & Aldehyde & $\mathrm{C}_{6} \mathrm{H}_{10} \mathrm{O}$ & 2-Hexanal & nd & $27.3 \pm 0.62$ & nd & LRI, MS, std \\
\hline 23 & 1290 & Terpene & $\mathrm{C}_{10} \mathrm{H}_{16}$ & $\alpha$-Terpinolene & $54.4 \pm 0.92$ & nd & $1250 \pm 21.2$ & LRI, MS, std \\
\hline 24 & 1321 & Alcohol & $\mathrm{C}_{6} \mathrm{H}_{14} \mathrm{O}$ & Hexanol & nd & $179 \pm 6.08$ & nd & LRI, MS, std \\
\hline 25 & 1360 & Ester & $\mathrm{C}_{10} \mathrm{H}_{20} \mathrm{O}_{3}$ & 1-Octenol acetate & nd & $2627 \pm 110$ & nd & LRI, MS, tent \\
\hline 26 & 1372 & Aldehyde & $\mathrm{C}_{9} \mathrm{H}_{18} \mathrm{O}$ & Nonanal & $128 \pm 3.2$ & nd & $79.4 \pm 1.98$ & LRI, MS, std \\
\hline 27 & 1402 & Acid & $\mathrm{C}_{2} \mathrm{H}_{4} \mathrm{O}_{2}$ & Acetic acid & nd & $665 \pm 22.6$ & $406 \pm 13.8$ & LRI, MS, std \\
\hline 28 & 1415 & Terpene & $\mathrm{C}_{10} \mathrm{H}_{16} \mathrm{O}$ & $\beta$-Thujone & $1008 \pm 41.3$ & nd & nd & LRI, MS, tent \\
\hline 29 & 1422 & Terpene & $\mathrm{C}_{10} \mathrm{H}_{16} \mathrm{O}$ & $\alpha$-Thujone & $113 \pm 2.37$ & nd & nd & LRI, MS, tent \\
\hline 30 & 1436 & Terpene & $\mathrm{C}_{10} \mathrm{H}_{18} \mathrm{O}_{2}$ & $(E)$ - linalool oxide & nd & $5448 \pm 168$ & $60.6 \pm 1.87$ & LRI, MS, tent \\
\hline 31 & 1445 & Alcohol & $\mathrm{C}_{8} \mathrm{H}_{16} \mathrm{O}$ & 1-Octen-3-ol & $178 \pm 5.34$ & nd & nd & LRI, MS, tent \\
\hline 32 & 1456 & Terpene & $\mathrm{C}_{10} \mathrm{H}_{18} \mathrm{O}_{2}$ & Epoxylinalool & nd & $469 \pm 10.7$ & nd & LRI, MS, std \\
\hline 33 & 1466 & Ester & $\mathrm{C}_{10} \mathrm{H}_{18} \mathrm{O}$ & Sabinene hydrate & nd & nd & $5224 \pm 88.8$ & LRI, MS, tent \\
\hline
\end{tabular}


Table 1. Cont.

\begin{tabular}{|c|c|c|c|c|c|c|c|c|}
\hline \multirow{2}{*}{ No } & \multirow{2}{*}{ LRI * } & \multirow{2}{*}{ Chemical Class } & \multirow{2}{*}{ Sum Formula } & \multirow{2}{*}{ Compounds } & \multicolumn{3}{|c|}{ Concentration $\left(\mu \mathrm{g} 100 \mathrm{~g}^{-1} \mathrm{dw}\right)^{\#}$} & \multirow{2}{*}{ Identification $\S$} \\
\hline & & & & & Salvia officinalis & Lavandula angustifolia & Mentha asiatica & \\
\hline 34 & 1495 & Terpene & $\mathrm{C}_{10} \mathrm{H}_{18} \mathrm{O}_{2}$ & (Z)-Linalool oxide & nd & $3809 \pm 129$ & nd & LRI, MS, tent \\
\hline 35 & 1515 & Terpene & $\mathrm{C}_{10} \mathrm{H}_{16} \mathrm{O}$ & Camphor & nd & $2769 \pm 116$ & nd & LRI, MS, std \\
\hline 36 & 1548 & Terpene & $\mathrm{C}_{10} \mathrm{H}_{18} \mathrm{O}$ & Linalool & $755 \pm 18.8$ & $19773 \pm 494$ & nd & LRI, MS, std \\
\hline 37 & 1564 & Ester & $\mathrm{C}_{12} \mathrm{H}_{20} \mathrm{O}_{2}$ & Linalyl acetate & $700 \pm 23.8$ & $13075 \pm 384$ & $3443 \pm 117$ & LRI, MS, tent \\
\hline 38 & 1596 & Ester & $\mathrm{C}_{12} \mathrm{H}_{20} \mathrm{O}_{2}$ & $\alpha$-Fenchyl acetate & nd & nd & $45.7 \pm 1.87$ & LRI, MS, tent \\
\hline 39 & 1603 & Terpene & $\mathrm{C}_{10} \mathrm{H}_{18} \mathrm{O}$ & 4-Terpineol & nd & nd & $5389 \pm 113$ & LRI, MS, std \\
\hline 40 & 1315 & Terpene & $\mathrm{C}_{15} \mathrm{H}_{24} \mathrm{O}$ & Caryophyllene & $2385 \pm 73.9$ & $1605 \pm 49.7$ & $1949 \pm 60.4$ & LRI, MS, std \\
\hline 41 & 1625 & Acid & $\mathrm{C}_{4} \mathrm{H}_{8} \mathrm{O}_{2}$ & Butyric acid & nd & $844 \pm 25.32$ & nd & LRI, MS, std \\
\hline 42 & 1638 & Terpene & $\mathrm{C}_{10} \mathrm{H}_{18} \mathrm{O}$ & $\Delta$-Terpineol & $428 \pm 9.84$ & nd & nd & LRI, MS, tent \\
\hline 43 & 1655 & Terpene & $\mathrm{C}_{15} \mathrm{H}_{24}$ & $\beta$-Farnesene & nd & $550 \pm 9.35$ & $78.7 \pm 1.33$ & LRI, MS, tent \\
\hline 44 & 1663 & Ester & $\mathrm{C}_{12} \mathrm{H}_{20} \mathrm{O}_{2}$ & Lavandulyl acetate & nd & $4241 \pm 144$ & nd & LRI, MS, std \\
\hline 45 & 1685 & Terpene & $\mathrm{C}_{10} \mathrm{H}_{18} \mathrm{O}$ & Lavandulol & nd & $1892 \pm 79.4$ & nd & LRI, MS, tent \\
\hline 46 & 1700 & Terpene & $\mathrm{C}_{10} \mathrm{H}_{18} \mathrm{O}$ & (Z)-Piperitol & nd & nd & $130 \pm 3.25$ & LRI, MS, tent \\
\hline 47 & 1714 & Terpene & $\mathrm{C}_{10} \mathrm{H}_{18} \mathrm{O}$ & $\alpha$-Terpineol & $1093 \pm 37.1$ & nd & $2135 \pm 72.5$ & LRI, MS, std \\
\hline 48 & 1720 & Terpene & $\mathrm{C}_{10} \mathrm{H}_{18} \mathrm{O}$ & Borneol & nd & $1731 \pm 70.9$ & nd & LRI, MS, std \\
\hline 49 & 1723 & Terpene & $\mathrm{C}_{15} \mathrm{H}_{24}$ & $\alpha$-Humulene & $687 \pm 14.4$ & nd & nd & LRI, MS, tent \\
\hline 50 & 1727 & Terpene & $\mathrm{C}_{10} \mathrm{H}_{14} \mathrm{O}$ & $d$-Carvone & nd & nd & $114 \pm 3.53$ & LRI, MS, std \\
\hline 51 & 1735 & Ester & $\mathrm{C}_{12} \mathrm{H}_{20} \mathrm{O}_{2}$ & Neryl acetate & nd & $237 \pm 7.11$ & nd & LRI, MS, tent \\
\hline 52 & 1742 & Terpene & $\mathrm{C}_{10} \mathrm{H}_{18} \mathrm{O}$ & (E)-piperitol & nd & nd & $273 \pm 6.27$ & LRI, MS, tent \\
\hline 53 & 1755 & Terpene & $\mathrm{C}_{15} \mathrm{H}_{24}$ & Bicyclogermacrene & nd & nd & $382 \pm 6.49$ & LRI, MS, tent \\
\hline 54 & 1769 & Terpene & $\mathrm{C}_{15} \mathrm{H}_{24}$ & $\alpha$-Farnesane & nd & $513 \pm 17.4$ & nd & LRI, MS, std \\
\hline 55 & 1808 & Aldehyde & $\mathrm{C}_{10} \mathrm{H}_{16} \mathrm{O}$ & 2-Decadienal & nd & nd & $53.4 \pm 2.24$ & LRI, MS, tent \\
\hline 56 & 1820 & Terpene & $\mathrm{C}_{10} \mathrm{H}_{12} \mathrm{O}$ & Anethole & nd & nd & $39.4 \pm 0.98$ & LRI, MS, std \\
\hline 57 & 1835 & Terpene & $\mathrm{C}_{10} \mathrm{H}_{14} \mathrm{O}$ & $p$-Cymen-8-ol & nd & $126 \pm 4.28$ & $38.9 \pm 1.32$ & LRI, MS, std \\
\hline 58 & 1860 & Terpene & $\mathrm{C}_{10} \mathrm{H}_{16} \mathrm{O}_{3}$ & Ascaridole & nd & nd & $66.4 \pm 2.72$ & LRI, MS, tent \\
\hline 59 & 1954 & Terpene & $\mathrm{C}_{15} \mathrm{H}_{24} \mathrm{O}$ & Caryophyllene oxide & nd & nd & $64.6 \pm 1.35$ & LRI, MS, tent \\
\hline 60 & 2028 & Acid & $\mathrm{C}_{8} \mathrm{H}_{16} \mathrm{O}_{2}$ & Octanoic acid & nd & nd & $7.51 \pm 0.23$ & LRI, MS, std \\
\hline 61 & 2102 & Terpene & $\mathrm{C}_{15} \mathrm{H}_{24} \mathrm{O}$ & Viridiflorol & $219 \pm 6.57$ & nd & nd & LRI, MS, tent \\
\hline 62 & 2162 & Terpene & $\mathrm{C}_{10} \mathrm{H}_{14} \mathrm{O}$ & Thymol & nd & nd & $31 \pm 0.71$ & LRI, MS, std \\
\hline 63 & 2219 & Terpene & $\mathrm{C}_{10} \mathrm{H}_{14} \mathrm{O}$ & Carvacrol & nd & nd & $49.8 \pm 0.84$ & LRI, MS, std \\
\hline 64 & 2450 & Hydrocarbon & $\mathrm{C}_{9} \mathrm{H}_{6} \mathrm{O}_{2}$ & Coumarin & nd & $229 \pm 7.78$ & nd & LRI, MS, tent \\
\hline 65 & 2930 & Acid & $\mathrm{C}_{16} \mathrm{H}_{32} \mathrm{O}_{2}$ & Palmitic acid & nd & $183 \pm 7.78$ & nd & LRI, MS, std \\
\hline 66 & 3184 & Acid & $\mathrm{C}_{18} \mathrm{H}_{34} \mathrm{O}_{2}$ & Oleic acid & $374 \pm 9.35$ & nd & nd & LRI, MS, std \\
\hline
\end{tabular}

* LRI, linear retention index calculated on a DB-WAX capillary column; ${ }^{*}$ Concentration: Results are the means of three repetitions as $\mu \mathrm{g} 100 \mathrm{~g}{ }^{-1} \mathrm{dw}$; ${ }^{\S}$ Identification: Methods of identification; LRI (linear retention index), MS tent. (tentatively identified by MS), Std (chemical standard); When only MS or LRI is available for the identification of a compound, it must be considered as an attempt of identification. nd (not detected). 


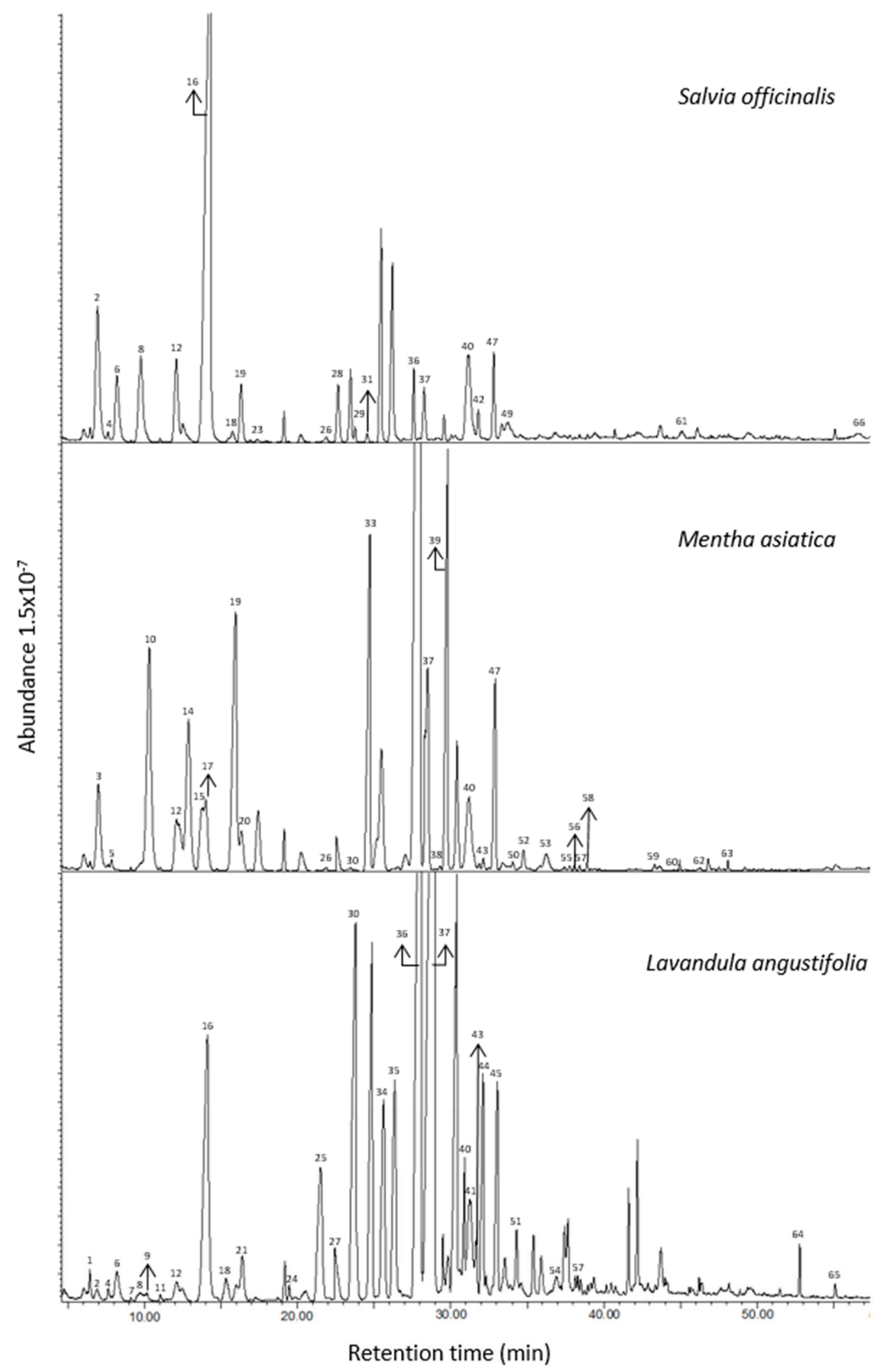

Figure 1. The gas chromatography-mass spectrometry (GC-MS) chromatograms of Salvia officinalis Lavandula angustifolia and Mentha asiatica (Peak numbers refer to Table 1). 
As previously designated, monoterpenes overwhelmingly affected the overall aroma characteristic of the S. officinalis by different researchers. Hayouni et al. [15] investigated the oil characterization of Tunusian S. officinalis. They found that major constituents were mainly oxygenated monoterpenes. In addition, the researchers pointed out that the major aroma compound of $S$. officinalis is 1,8-cineole with $33.27 \%$ of the total compounds being identified. Likewise, research from different locations previously identified these compounds as the major aroma compounds of $S$. officinalis [16-18].

Another studied member of Lamiaceae was M. asiatica. Sabinene together with $\gamma$-terpinene and 4-terpineol were detected as the major terpene compounds in this herb. These terpenes were identified in M. asiatica and different species of Mentha spp. from a different location in previous studies [7,19]. Verma et al. [7] reported that the aroma compounds identified in the studied Mentha spp. are oxygenated monoterpenes $(74.0 \%)$ and sesquiterpene hydrocarbons $(18.0 \%)$ with lower amounts of monoterpene hydrocarbons (2.6\%). Terpene synthases are directly responsible for the production of these volatile terpenes.

On the other hand, some of them are formed via modification of the main skeletons of terpene made by terpene synthases by hydroxylation, dehydrogenation, acylation, and other reactions [20]. The last member of Lamiaceae studied was L. angustifolia. The main terpene compounds of the sample were linalool, 1,8-cineole and (Z)-linalool oxide. Similar to our study, previously published studies highlighted that linalool is the most abundant compound in the L. angustifolia [21-23]. This compound is an oxygenated monoterpene and one of the main compound of essential oils in various aromatic species. These linalool rich species have been used in traditional medical systems since prehistoric times [1]. Furthermore, previous articles pointed out that this compound acts as a reversible competitive inhibitor of acetylcholinesterase, has been an alternative to conventional insecticides and has dose-dependent marked sedative effects on the central nervous system [24-26].

Esters were the second most important class of the aroma compounds in the Lamiaceae family. Esters compounds have a very wide range of odor and flavoring effects and there are over 200 of these compounds permitted for use in foods. Moreover, these compounds are widely distributed in essential oils and in some instances represent the major constituent. Generally, ester compounds are responsible for the mature and fruity notes [27]. A total of seven esters were identified and quantified in herbs: two in S. officinalis, five in L. angustifolia and three in M. asiatica. Linalyl acetate was the only compounds which was detected in all samples. This compound is one of the major compounds that characterized the overall aroma of the L. angustifolia [22]. Linalyl acetate is a significant compound in the perfume industry and is found in large amounts in various plants [28].

Regarding the other compounds, in trace amounts, acids, alcohols, aldehydes and hydrocarbons were also identified and quantified in the three samples. These compounds account for $0.01 \%, 0.03 \%$ and $0.01 \%$ of total aroma compounds, which were identified in S. officinalis, L. angustifolia and M. asiatica, respectively. Most of these volatiles were previously identified in these three members of the Lamiaceae family $[7,16,17,23,24,29]$.

\section{Conclusions}

In the present paper, the aim was to determine the aroma compounds of three members of the Lamiaceae, Salvia officinalis, Lavandula angustifolia and Mentha asiatica, cultivated in the Turkey. A total of 23, 33, and 33 aroma compounds were identified in Salvia officinalis Lavandula angustifolia and Mentha asiatica, respectively including, acids, alcohols, aldehydes, esters, hydrocarbons, and terpenes. Terpene compounds were determined as the main chemical group among the identified aroma compounds, followed by esters. A total of 17 terpene compounds were identified in S. officinalis, 18 in L. angustifolia and 25 in M. asiatica. Linalyl acetate was the only and most important ester compound which was detected in all samples.

Acknowledgments: We also wish to thank Bryan Christiansen from Global Research Society, New York, USA for his outstanding editing and proof reading. 
Author Contributions: S.S., H.K., and A.S.S. conceived and planned the experiments. A.S.S. and H.K. performed the experiments and analyzed the data. A.S.S. and S.S. wrote the manuscript. H.K. were involved in discussions of the experimental results and critical editing of the manuscript. All authors read and approved the final manuscript.

Conflicts of Interest: The authors declare no conflict of interest.

\section{References}

1. Naghibi, F.; Mosaddegh, M.; Mohammadi Motamed, M.; Ghorbani, A. Labiatae family in folk medicine in Iran: From ethnobotany to pharmacology. Iran. J. Pharm. Res. 2010, 4, 63-79.

2. Jamzad, Z.; Ingrouille, M.; Simmonds, M.S. Three new species of Nepeta (Lamiaceae) from Iran. Taxon 2003, 52, 93-98. [CrossRef]

3. Nunez, D.; De Castro, C.O. Palaeoethnobotany and archaeobotany of the Labiatae in Europe and the near East. In Advances in Labiatae Science; Royal Botanic Gardens, Kew: London, UK, 1992; p. 437.

4. Adam, K.; Sivropoulou, A.; Kokkini, S.; Lanaras, T.; Arsenakis, M. Antifungal activities of Origanum vulgare subsp. hirtum, Mentha spicata, Lavandula angustifolia, and Salvia fruticosa essential oils against human pathogenic fungi. J. Agric. Food Chem. 1998, 46, 1739-1745. [CrossRef]

5. Büyükokuroğlu, M.E.; Gepdiremen, A.; Hacimüftüoğlu, A.; Oktay, M. The effects of aqueous extract of Lavandula angustifolia flowers in glutamate-induced neurotoxicity of cerebellar granular cell culture of rat pups. J. Ethnopharmacol. 2003, 84, 91-94. [CrossRef]

6. Bagci, E.; Kocak, A. Essential oil composition of the aerial parts of two Salvia L. (S. multicaulis Vahl. Enum and S. tricochlada Bentham) species from East Anatolian Region (Turkey). Int. J. Sci. Tech. 2008, 1, $13-18$.

7. Verma, R.S.; Pandey, V.; Chauhan, A.; Tiwari, R. Essential oil composition of Mentha longifolia (L.) L. collected from Garhwal Region of Western-Himalaya. J. Essent. Oil Bear. Plants 2015, 18, 957-966. [CrossRef]

8. Patel, A.; Pandey, V.; Patra, D. Metal absorption properties of Mentha spicata grown under tannery sludge amended soil-its effect on antioxidant system and oil quality. Chemosphere 2016, 147, 67-73. [CrossRef] [PubMed]

9. Inouye, S.; Uchida, K.; Yamaguchi, H.; Miyara, T.; Gomi, S.; Amano, M. Volatile aroma constituents of three Labiatae herbs growing wild in the Karakoram-Himalaya district and their antifungal activity by vapor contact. J. Essent. Oil Res. 2001, 13, 68-72. [CrossRef]

10. Breitmaier, E. Terpenes: Importance, general structure, and biosynthesis. In Terpenes: Flavors, Fragrances, Pharmaca, Pheromones; Wiley-VCH Verlag GmbH \& Co. KGaA: Weinheim, Germany, 2006; pp. 1-9.

11. Rodríguez-Bencomo, J.J.; Kelebek, H.; Sonmezdag, A.S.; Rodríguez-Alcalá, L.M.; Fontecha, J.; Selli, S. Characterization of the aroma-active, phenolic, and lipid profiles of the pistachio (Pistacia vera L.) nut as affected by the single and double roasting process. J. Agric. Food Chem. 2015, 63, 7830-7839. [CrossRef] [PubMed]

12. Sonmezdag, A.S.; Kelebek, H.; Selli, S. Characterization of aroma-active and phenolic profiles of wild thyme (Thymus serpyllum) by GC-MS-Olfactometry and LC-ESI-MS/MS. J. Food Sci. Technol. 2016, 53, 1957-1965. [CrossRef] [PubMed]

13. Guclu, G.; Sevindik, O.; Kelebek, H.; Selli, S. Determination of volatiles by odor activity value and phenolics of cv. Ayvalik early-harvest olive oil. Foods 2016, 5, 46. [CrossRef]

14. Méndez-Tovar, I.; Novak, J.; Sponza, S.; Herrero, B.; Asensio-S-Manzanera, M. Variability in essential oil composition of wild populations of Labiatae species collected in Spain. Ind. Crop. Prod. 2016, 79, 18-28. [CrossRef]

15. Hayouni, E.A.; Chraief, I.; Abedrabba, M.; Bouix, M.; Leveau, J.-Y.; Mohammed, H.; Hamdi, M. Tunisian Salvia officinalis L. and Schinus molle L. essential oils: Their chemical compositions and their preservative effects against Salmonella inoculated in minced beef meat. Int. J. Food Microbiol. 2008, 125, 242-251. [CrossRef] [PubMed]

16. Edris, A.E.; Jirovetz, L.; Buchbauer, G.; Denkova, Z.; Stoyanova, A.; Slavchev, A. Chemical composition, antimicrobial activities and olfactive evaluation of a Salvia officinalis L.(sage) essential oil from Egypt. J. Essent. Oil Res. 2007, 19, 186-189. [CrossRef]

17. Bouaziz, M.; Yangui, T.; Sayadi, S.; Dhouib, A. Disinfectant properties of essential oils from Salvia officinalis L. cultivated in Tunisia. Food Chem. Toxicol. 2009, 47, 2755-2760. [CrossRef] [PubMed] 
18. Vera, R.; Chane-Ming, J.; Fraisse, D. Chemical composition of the essential oil of sage (Salvia officinalis L.) from Reunion Island. J. Essent. Oil Res. 1999, 11, 399-402. [CrossRef]

19. Baser, K.; Nuriddinov, K.R.; Nigmatullaev, A.; Aripov, K.N. Essential oil of Mentha asiatica Boriss. from Uzbekistan. J. Essent. Oil Res. 1997, 9, 453-454. [CrossRef]

20. Dudareva, N.; Pichersky, E.; Gershenzon, J. Biochemistry of plant volatiles. Plant. Physiol. Biochem. 2004, 135, 1893-1902. [CrossRef] [PubMed]

21. Guitton, Y.; Nicolè, F.; Moja, S.; Valot, N.; Legrand, S.; Jullien, F.; Legendre, L. Differential accumulation of volatile terpene and terpene synthase mRNAs during lavender (Lavandula angustifolia and L. $\mathrm{x}$ intermedia) inflorescence development. Physiol. Plant. 2010, 138, 150-163. [CrossRef] [PubMed]

22. Perrucci, S.; Macchioni, G.; Cioni, P.; Flamini, G.; Morelli, I.; Taccini, F. The activity of volatile compounds from Lavandula angustifolia against Psoroptes Cuniculi. Phytother. Res. 1996, 10, 5-8. [CrossRef]

23. Da Porto, C.; Decorti, D.; Kikic, I. Flavour compounds of Lavandula angustifolia L. to use in food manufacturing: Comparison of three different extraction methods. Food Chem. 2009, 112, 1072-1078. [CrossRef]

24. Jirovetz, L.; Jäger, W.; Buchbauer, G.; Nikiforov, A.; Raverdinno, V. Investigations of animal blood samples after fragrance drug inhalation by gas chromatography/mass spectrometry with chemical ionization and selected ion monitoring. Biol. Mass Spectrom. 1991, 20, 801-803. [CrossRef] [PubMed]

25. Ryan, M.; Byrne, O. Plant-insect coevolution and inhibition of acetylcholinesterase. J. Chem. Eco. 1988, 14, 1965-1975. [CrossRef] [PubMed]

26. Hink, W.; Liberati, T.; Collart, M. Toxicity of linalool to life stages of the cat flea, Ctenocephalides felis (Siphonaptera: Pulicidae), and its efficacy in carpet and on animals. J. Med. Entomol. 1988, 25, 1-4. [CrossRef] [PubMed]

27. Reineccius, G. Flavor Chemistry and Technology; CRC Press: Boca Raton, FL, USA, 2005.

28. Casabianca, H.; Graff, J.; Faugier, V.; Fleig, F.; Grenier, C. Enantiomeric distribution studies of linalool and linalyl acetate. A powerful tool for authenticity control of essential oils. J. High Resolut. Chromatogr. 1998, 21, 107-112. [CrossRef]

29. El-Zaeddi, H.; Martínez-Tomé, J.; Calín-Sánchez, Á.; Burló, F.; Carbonell-Barrachina, Á.A. Volatile Composition of Essential Oils from Different Aromatic Herbs Grown in Mediterranean Regions of Spain. Foods 2016, 5, 41. [CrossRef] 